\title{
Modernidad y pensamiento descolonizador
}

\section{Xavier Ricard}

\section{CpenEdition}

\section{Journals}

Edición electrónica

URL: http://journals.openedition.org/bifea/5686

DOI: 10.4000/bifea.5686

ISSN: 2076-5827

\section{Editor}

Institut Français d'Études Andines

\section{Edición impresa}

Fecha de publicación: 1 mayo 2005

Paginación: 135-136

ISSN: 0303-7495

\section{Referencia electrónica}

Xavier Ricard, « Modernidad y pensamiento descolonizador». Bulletin de l'Institut français d'études andines [En línea], 34 (1) | 2005, Publicado el 08 abril 2005, consultado el 11 diciembre 2020. URL http://journals.openedition.org/bifea/5686 ; DOI : https://doi.org/10.4000/bifea.5686

\section{(c) (i) (9)}

Les contenus du Bulletin de l'Institut français d'études andines sont mis à disposition selon les termes de la licence Creative Commons Attribution - Pas d'Utilisation Commerciale - Pas de Modification 4.0 International. 


\section{MODERNIDAD Y PENSAMIENTO DESCOLONIZADOR}

El seminario Modernidad y Pensamiento Descolonizador, organizado en La Paz (Bolivia) los dias 18 y 19 de mayo de 2005, por el grupo de investigación sobre ModernidadColonialidad (integrado, entre otros, por Walter Mignolo — Universidad de Duke- y Javier Sanjinés — Universidad de Michigan-), y auspiciado por el IFEA y la Embajada de Francia en Bolivia, permitió a un grupo de investigadores provenientes del Perú, Ecuador, Bolivia, Brasil y Estados Unidos debatir acerca de la posibilidad de «descolonizar» el pensamiento latino-americano, a partir de un movimiento de «desprendimiento» del discurso y la práctica de la modernidad europea hegemómica. Un público muy numeroso participó en el debate, de manera muy intensa, lo cual puso en evidencia la actualidad de esta 
discusión académicoa en el contexto de movilización social que atraviesa actualmente Bolivia. Quisiera en estas breves líneas esbozar un comentario crítico frente al proyecto intelectual y político que originó el seminario.

Como hemos señalado, la propuesta teórica del grupo de investigación sobre ModernidadColonialidad radica, en suma, en elaborar un «pensamiento propio» latinoamericano, y para empezar, indígena, frente al discurso de la modernidad hegemónica. El problema empieza cuando se intenta poner el proyecto en ejecución. En primer lugar, este pensamiento propio sabe lo que no es (la modernidad hegemónica) pero no sabe lo que es, ni cómo construirse. Sobre este punto, en el seminario existieron serias dificultades de interlocución entre intelectuales académicos e intelectuales indígenas, que proponían muy a menudo esencializaciones («los aymara, etc.»), sin el más mínimo sentido crítico, sin información histórica, ni antropológica. En suma, proponían ideologías, además muy carentes de contenidos, y se dedicaban más bien a criticar la modernidad desde una perspectiva voluntariamente ex-centrada, externa, posición muy cómoda por cierto pero que ponía en relieve, a mi juicio, su falta de conocimiento acerca de esta modernidad y sus complejidades. Por otra parte, se ocultó, o se quizo pasar por alto, la diferencia epistemológica fundamental entre la modernidad y el pensamiento no-moderno: el hecho de que la modernidad se constituya, desde el inicio, como pensamiento de lo universal, es decir como un pensamiento que abarca la diversidad fenomenal del «universo», o que debe poder englobar toda la fenomenalidad. Esto es el rasgo epistemológico constitutivo del pensamiento moderno, y de ahí se deriva su vínculo orgánico con la expansión del capitalismo mundial. En otros términos, si la modernidad es universal, no es porque ha ido de la mano con un proyecto de dominación a escala mundial (es decir, no es un pensamiento provinciano que se expandió por razones accidentales), sino que su expansión fue posible porque sus bases epistemológicas permitían, y hasta exigían, que se extendiera su campo de efectivización por todo el planeta.

Esta observación tiene consecuencias importantes. Por ejemplo, no basta proclamar que el pensamiento moderno tiene falsas pretensiones a la universalidad, y que hay que oponerse a él, y a la lógica de poder que lo sostiene para abrir espacio para un «pensamiento otro», y finalmente, exigir el abandono de toda pretensión a la universalidad, de cualquier pensamiento. Es decir, exigir la substitución del pensamiento universal por un mosaico de pensamientos particulares articulados entre sí por referentes abstractos y sin contenido como «igualdad». El problema es mucho más complejo: hay que poder establecer un diálogo crítico con esta modernidad, pero reconociendo su particularidad epistemológica, que la hace diferente de cualquier otro tipo de saberes, no tanto en sus contenidos (muchos saberes también permiten englobar la variabilidad de la fenomenalidad — piénsese por ejemplo en la medicina china, o en la ontología quechua-), pero sí en sus mecanismos de elaboración, y por tanto en su estructura epistemológica. La modernidad es una máquina de absorbsión de la diversidad de la fenomenalidad, que se piensa a sí misma como tal, y que constantemente afina sus herramientas interpretativas para lograr sus fines. Esta absorbsión de lo diverso no es un resultado secundario, un efecto colateral del pensamiento moderno, sino su fin, su razón de ser.

Segundo, corolario de lo anterior, no se puede uno quedar diciendo: «ya no hay que hablar de creencias indígenas, de representaciones indígenas. iEsto es un lastre de la colonialidad! Hay que hablar de saberes indígenas, de conocimiento indígena». Sin discutir la episteme indígena, sin saber, o sin debatir, respecto a las razones por las cuales existe una diferencia entre conocimiento y creencias, representaciones. Me parece que hay una demagogia enorme en todo este «nivelamiento» in abstracto, sin mayor análisis, entre dos formas de pensamiento muy distintas. 